Abstracta Iranicacta Iranica

Revue bibliographique pour le domaine irano-aryen

Volume 40-41 | 2019

Comptes rendus des publications de 2017-2018

\title{
Javier Alvarez-Mon, Gian Pietro Basello, Yasmina Wicks (eds.). The Elamite World
}

\section{Rémy Boucharlat}

\section{(2) OpenEdition}

12 Journals

\section{Édition électronique}

URL : http://journals.openedition.org/abstractairanica/49908

DOI : 10.4000/abstractairanica.49908

ISBN : 1961-960X

ISSN : 1961-960X

Éditeur :

CNRS (UMR 7528 Mondes iraniens et indiens), Éditions de l'IFRI

Référence électronique

Rémy Boucharlat, « Javier Alvarez-Mon, Gian Pietro Basello, Yasmina Wicks (eds.). The Elamite World», Abstracta Iranica [En ligne], Volume 40-41 | 2019, document 2, mis en ligne le 30 décembre 2019, consulté le 17 avril 2021. URL : http://journals.openedition.org/abstractairanica/49908 ; DOI : https:// doi.org/10.4000/abstractairanica.49908

Ce document a été généré automatiquement le 17 avril 2021.

Tous droits réservés 


\title{
Javier Alvarez-Mon, Gian Pietro Basello, Yasmina Wicks (eds.). The Elamite World
}

\author{
Rémy Boucharlat
}

\section{RÉFÉRENCE}

Javier Alvarez-Mon, Gian Pietro Basello, Yasmina Wicks (eds.). The Elamite World.

London \& New York: Routledge, 2018, 868 p., ill.

1 Cet ouvrage imposant vient peu après The Archaeology of Elam: Formation and Transformation of an Ancient Iranian State de D.T. Potts, paru en 1999, mais considérablement enrichi et actualisé dans la seconde édition en 2016. Le livre comblait une lacune depuis des publications des années 1960 à 1980. Un seul auteur, Potts, reprenait l'ensemble des publications surtout archéologiques et en donnait en plus de 400 pages de ce que fut l'Elam en une série de chapitres arrangés selon la chronologie, un Elam pris au sens large dès avant 3000 av. J.C., et débordant sur la période perse et au-delà jusqu'à conquête islamique.

2 Les éditeurs de The Elamite World ont adopté un tout autre parti : ils ont sollicité des contributions d'une quarantaine d'auteurs et ont réparti les chapitres selon les spécialités de chacun, historiens, archéologues, philologues, épigraphistes, historiens d'art, environnementalistes, spécialistes de technologie et artisanat, etc. Ce sont plus de 800 pages concentrées sur l'Elam historique qui offrent de grandes divisions thématiques distribuées dans huit grandes parties, ou des thèmes plus précis ou des tranches d'histoire proposés dans des chapitres. Dans cette longue histoire, on cite ici quelques chapitres seulement concernant Abstracta, ceux qui traitent directement de l'époque néo-élamite tardive, donc pré-achéménide, voire l'héritage élamite chez les Achéménides, mais les thèmes de beaucoup d'autres chapitres abordent partiellement la fin de l'Elam. 
3 Jan Tavernier (Part II chap. 9, "Elamites and Iranians ", p. 163-174 défend la thèse généralement acceptée, selon laquelle les Perses de la première moitié du Ier millénaire vivaient dans une région faisant partie du royaume néo-élamite - mais est-ce encore le cas du payas d'Anshan? et étaient-ils réellement soumis aux Elamites ou tolérés ailleurs? Après une période d'acculturation la culture élamo-iranienne devint prédominante. Tavernier traite des noms propres et des emprunts iraniens dans la période néo-élamite à partir des tablettes dites de l'Acropole (de Suse) qui datent du début du VIe s.

4 Elynn Gorris and Yasmina Wicks (Part III chap. 13, "The last centuries of Elam : the Neo-Elamite period », p. 249- 272), historienne pour la première et archéologue pour la seconde, abordent par les textes et les données archéologiques la dernière période, la première moitié du Ier millénaire av. J.C. dans la série de chapitres chronologiques. Les dynasties et la succession - ou contemporanéité pour - des souverains restent des questions très débattues pour les VIII-VIIe s., d'après les textes néo-assyriens et ceux des tablettes de l'Acropole de Suse pour la fin de la période. Les données archéologiques assez confuses à Suse, faute de fouilles de qualité jusqu'aux années 1960, sont largement complétées aujourd'hui par les découvertes dans la partie orientale de la plaine, sites sondés et découverte fortuite de riches tombes, comme à Arjan et Jubaji, mais aussi des cimetières dans les montagnes. S'y ajoutent des bas-reliefs ainsi que de probables lieux de culte en plein air (Kurangun, Naqsh-i Rustam) thème que traite une section «First millennium » du chapitre de J. Álvarez-Mon, «The sculptural arts of Elam », p. 617-622.

5 Mark B. Garrison (Part VI chap. 32 "Glyptic in the 1st millennium », p. 649-672) spécialiste depuis longtemps de la glyptique achéménide et de ses antécédents, il était le mieux placé pour traiter celle de l'époque néo-élamite en insistant sur les représentations qui annoncent l'iconographie achéménide.

Wouter F.M. Henkelman, (Part VIII, chap. 39 «Elamite administrative and religious heritage in the Persian heartland ", p. 803-828) considère les documents écrits qui rendent compte de cet héritage, tandis que Javier Álvarez-Mon (Part VIII, chap. 40 "The Elamite artistic heritage of Persia », p. 829-850) prend en compte l'architecture et les représentations.

\section{AUTEURS}

\section{RÉMY BOUCHARLAT}

UMR 5133 CNRS-Université de Lyon 